\title{
1 Variations in the Influence of Diffuse Light on Gross Primary Productivity in Temperate
}

\section{Ecosystems}

3 Susan J. Cheng ${ }^{\mathrm{a},{ }^{*}}$, Gil Bohrer ${ }^{\mathrm{b}}$, Allison L. Steiner ${ }^{\mathrm{c}}$, David Y. Hollinger ${ }^{\mathrm{d}}$, Andrew Suyker ${ }^{\mathrm{e}}$,

4 Richard P. Phillips ${ }^{\mathrm{f}}$, Knute J. Nadelhoffer ${ }^{\mathrm{a}}$

5

$6 \quad{ }^{a}$ Department of Ecology and Evolutionary Biology, University of Michigan, Ann Arbor, MI

7 48109, USA

$8{ }^{\mathrm{b}}$ Department of Civil, Environmental and Geodetic Engineering, The Ohio State University,

9 Columbus, OH 43210, USA

$10{ }^{c}$ Department of Atmospheric, Oceanic and Space Sciences, University of Michigan, Ann Arbor,

11 MI 48109, USA

$12{ }^{\mathrm{d}}$ Northern Research Station, USDA Forest Service, Durham, NH 03824, USA

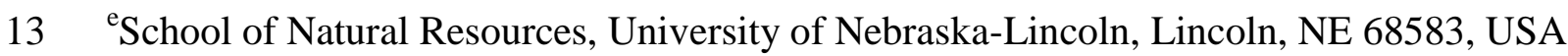

14 f Department of Biology, Indiana University, Bloomington, IN 47405, USA

15

$16 *$ Corresponding author: e-mail address: chengs@ umich.edu, tel: +1 17346473165 


\section{Abstract}

The carbon storage potential of terrestrial ecosystems depends in part on how

19 atmospheric conditions influence the type and amount of surface radiation available for

20 photosynthesis. Diffuse light, resulting from interactions between incident solar radiation and

21 atmospheric aerosols and clouds, has been postulated to increase carbon uptake in terrestrial

22 ecosystems. However, the magnitude of the diffuse light effect is unclear because existing

23 studies use different methods to derive above-canopy diffuse light conditions. We used site-

24 based, above-canopy measurements of diffuse light and gross primary productivity (GPP) from

25 ten temperate ecosystems (including mixed conifer forests, deciduous broadleaf forests, and

26 croplands) to quantify the GPP variation explained by diffuse photosynthetically active radiation

27 (PAR) and to calculate increases in GPP as a function of diffuse light. Our analyses show that

28 diffuse PAR explained up to $41 \%$ of variation in GPP in croplands and up to $17 \%$ in forests,

29 independent of direct light levels. Carbon enhancement rates in response to diffuse PAR

30 (calculated after accounting for vapor pressure deficit and air temperature) were also higher in

31 croplands $\left(0.011-0.050 \mu \mathrm{mol} \mathrm{CO}_{2}\right.$ per $\mu \mathrm{mol}$ photons of diffuse PAR) than in forests $(0.003-0.018$

$32 \mu \mathrm{mol} \mathrm{CO}_{2}$ per $\mu \mathrm{mol}$ photons of diffuse PAR). The amount of variation in GPP and carbon

33 enhancement rate both differed with solar zenith angle and across sites for the same plant

34 functional type. At crop sites, diffuse PAR had the strongest influence and the largest carbon

35 enhancement rate during early mornings and late afternoons when zenith angles were large, with

36 greater enhancement in the afternoons. In forests, diffuse PAR had the strongest influence at

37 small zenith angles, but the largest carbon enhancement rate at large zenith angles, with a trend

38 in ecosystem-specific responses. These results highlight the influence of zenith angle and the 
39 role of plant community composition in modifying diffuse light enhancement in terrestrial

40 ecosystems, which will be important in scaling this effect from individual sites to the globe.

\section{Keywords}

42 Net ecosystem exchange; diffuse PAR; carbon cycling; land-atmosphere interactions

43

44

45

46

47

48 


\section{Introduction}

Forests are estimated to remove up to $27 \%$ of human-emitted $\mathrm{CO}_{2}$ annually $(2.6 \pm 0.8 \mathrm{Gt}$

$51 \mathrm{C} \mathrm{yr}^{-1}$ ), with temperate forests responsible for about half of this uptake globally (Le Quéré et al.,

52 2013; Sarmiento et al., 2010). It is uncertain how this amount of carbon uptake will change in

53 the future because forest carbon processes are affected by complex interactions driven by

54 changes in climate and natural- and human-caused shifts in plant species composition and

55 canopy structure. Isolating and quantifying the impacts of individual drivers of land-atmosphere

$56 \mathrm{CO}_{2}$ exchange could improve these calculations of the future terrestrial carbon sink.

57 One important factor influencing photosynthesis and hence forest $\mathrm{CO}_{2}$ uptake is light

58 availability. Rates of leaf-level $\mathrm{CO}_{2}$ uptake increase with solar radiation until leaves are light

59 saturated (Mercado et al., 2009). This implies that forest $\mathrm{CO}_{2}$ uptake is greater on sunny days

60 when leaves are fully exposed to direct light. However, increases in diffuse light, which is

61 produced when clouds and aerosols interact with and scatter incoming solar radiation, may be

62 even more beneficial than equal increases in direct light. At the ecosystem level, key processes

63 related to photosynthesis, including gross primary productivity (GPP), net ecosystem exchange

64 (NEE), and light-use efficiency (LUE), can increase in magnitude when the proportion of light

65 entering a forest canopy is more diffuse (Gu et al., 1999b; Hollinger et al., 1994; Jenkins et al.,

66 2007; Oliphant et al., 2011; Urban et al., 2012; Zhang et al., 2011). In addition, global

67 simulations from 1960-1999 indicate that increases in the proportion of diffuse light reaching

68 plant canopy surfaces may have amplified the global land carbon sink by $24 \%$ (Mercado et al.,

69 2009).

Several mechanisms have been proposed to explain how diffuse light increases

71 ecosystem $\mathrm{CO}_{2}$ uptake and LUE. First, diffuse light can penetrate deeper into a forest canopy 
72 and reach lower canopy leaves that would normally be light-limited on clear days when light is

73 mostly direct (Hollinger et al., 1994; Oliphant et al., 2011). Second, the same amount of light is

74 distributed across more leaves when diffuse light is dominant, which can minimize light

75 saturation and photo-inhibition of upper canopy leaves and increase canopy LUE or

76 photosynthesis (Gu et al., 2002; Knohl and Baldocchi, 2008). Third, diffuse light can create

77 conditions favorable for photosynthesis by reducing water and heat stress on plants (Steiner and

78 Chameides, 2005; Urban et al., 2012). Finally, a fourth hypothesis suggests that diffuse light has

79 a higher ratio of blue to red light, which may stimulate photochemical reactions and stomatal

80 opening (Urban et al., 2012).

81 There is no consensus regarding the magnitude of effect that diffuse light has on

82 ecosystem carbon processing. Studies using derived values of diffuse light suggest that LUE is

83 higher when most incident light is diffuse and can result in maximum carbon uptake under

84 moderate cloud cover (Gu et al., 2002; Min and Wang, 2008; Rocha et al., 2004). However,

85 studies using a three-dimensional canopy model and a land surface scheme predict that diffuse

86 radiation will not lead to significant increases in carbon uptake on cloudy days as compared to

87 clear days because of reductions in total shortwave radiation (Alton et al., 2005; Alton et al.,

88 2007). If clouds decrease surface radiation enough to lower total canopy photosynthetic activity,

89 this could offset any potential GPP gain resulting from increased LUE under diffuse light

90 conditions (Alton, 2008).

91 Several studies using measurements of diffuse light support the hypothesis that LUE is

92 higher under diffuse light, consistent with studies using derived diffuse light data (Dengel and

93 Grace, 2010; Jenkins et al., 2007). In addition, total carbon uptake can be greater under cloudy,

94 diffuse light conditions compared to clear skies in three forest types (Hollinger et al., 1994; Law 
95 et al., 2002). Aerosol-produced diffuse light also leads to an increase in the magnitude of NEE

96 in forests and croplands (Niyogi et al., 2004). Additional observation-based analyses indicate

97 that diffuse light increases carbon uptake when compared to the same level of direct light, but

98 also when total light levels decrease (Hollinger et al., 1994; Urban et al., 2007; Urban et al.,

99 2012).

100 The magnitude of the diffuse light effect on terrestrial carbon uptake may depend on

101 ecosystem type or canopy structural characteristics. A regional modeling study suggests that

102 diffuse light can increase net primary productivity (NPP) in mixed and broadleaf forests, but has

103 a negligible effect on croplands (Matsui et al., 2008). Another study using derived diffuse light

104 data suggests that LUE increases with diffuse light, and that differences among ecosystems are

105 potentially dependent on vegetation canopy structure (Zhang et al., 2011). The influences of

106 ecosystem type and vegetation structure are also supported by an observation-based study

107 showing that under diffuse light, $\mathrm{CO}_{2}$ flux into a grassland decreased, but increased by different

108 amounts in croplands depending on the species of crop planted (Niyogi et al., 2004). However,

109 another study using derived diffuse light data found no difference in the effect of patchy clouds

110 on LUE among 23 grassland, prairie, cropland, and forest ecosystems in the Southern Great

111 Plains (Wang et al., 2008). Inconsistencies among these studies may be due to differences in the

112 methods and models used to obtain diffuse light or sky conditions and assess their impacts on

113 ecosystem carbon processing (Gu et al., 2003).

114 Climate modelers have begun incorporating the influence of diffuse light on ecosystem

115 carbon uptake into land surface schemes as more details of canopy structure are added to models

116 (Bonan et al., 2012; Dai et al., 2004; Davin and Seneviratne, 2012). Our study provides insight

117 into the importance of diffuse light on ecosystem carbon processing for improving projections of 
118 the terrestrial carbon sink. We seek here to 1) quantify how much variation in ecosystem GPP is

119 explained by diffuse light, independent of direct radiation levels, 2) compare the influence of

120 diffuse light on GPP among temperate ecosystems differing in canopy structure and species

121 composition, and 3) determine the strength of diffuse light enhancement of GPP while

122 accounting for its correlation with zenith angle, vapor pressure deficit (VPD), and air

123 temperature. Unlike many previous studies (Alton, 2008; Butt et al., 2010; Gu et al., 1999b; Min

124 and Wang, 2008; Zhang et al., 2010), we drive our analyses only with direct field measurements

125 of diffuse light, rather than with derived values from radiation partitioning models, which may be

126 biased by incorrect representations of clouds and aerosols. Finally, our paper highlights the

127 changes in the diffuse light effect across the diurnal cycle and the role of time of day on the

128 diffuse light enhancement in terrestrial ecosystems, which will be important in scaling this effect

129 from individual sites to the globe.

130 2. Materials and Methods

$131 \quad 2.1$ Data Sources

132 All analyzed data were collected and processed by investigators participating in the

133 AmeriFlux program (http://ameriflux.lbl.gov/), a network of meteorological towers in the United

134 States (U.S.) that measures net fluxes of water vapor and $\mathrm{CO}_{2}$ between the land surface and the

135 atmosphere and corresponding meteorological, soil, and vegetation conditions (Baldocchi, 2003).

136 Data collection, analysis, and metadata are standardized, reviewed, and quality controlled by

137 AmeriFlux for all sites. GPP is calculated by subtracting the modeled ecosystem respiration

138 from observed NEE. Respiration is modeled empirically based on NEE observations during the

139 night, when GPP is assumed to be zero. We focus our study on GPP instead of another measure

140 of carbon processing because it describes ecosystem $\mathrm{CO}_{2}$ uptake, is affected directly by 
141 radiation, and is the first step in processing atmospheric $\mathrm{CO}_{2}$ into long-term storage in

142 ecosystems.

$143 \quad 2.2$ Site Selection

144 We selected temperate AmeriFlux sites within the contiguous U.S. with at least three 145 years of Level 2 (processed and quality controlled) NEE and GPP. Among these, we specifically

146 selected sites that contain equipment to measure above-canopy total and diffuse

147 photosynthetically active radiation (PAR, 400-700 nm) and report at least three years of diffuse

148 PAR values to AmeriFlux. For the University of Michigan Biological Station (UMBS), we

149 obtained updated total and diffuse PAR data from site coordinators that were not yet available on

150 the AmeriFlux website at the time of our analyses. After separating sites with crop rotations by

151 species, there were sufficient data for ten sites covering three ecosystem types, including mixed

152 forest (Howland Logged, Howland N Fertilized, Howland Reference), deciduous broadleaf forest

153 (Morgan Monroe and UMBS), and cropland (Mead Irrigated Maize, Mead Irrigated Rotation:

154 Maize, Mead Irrigated Rotation: Soybean, Mead Rainfed Rotation: Maize, Mead Rainfed

155 Rotation: Soybean). Site characteristics and data availability are listed in Table 1. 
156 Table 1: AmeriFlux site information and ecosystem characteristics

\begin{tabular}{|c|c|c|c|c|c|c|c|c|c|}
\hline $\begin{array}{c}\text { Site } \\
\text { (SitelD) }\end{array}$ & $\begin{array}{l}\text { Lat, Lon } \\
\left({ }^{\circ}\right)\end{array}$ & $\begin{array}{l}\text { Years of } \\
\text { Data }\end{array}$ & $\begin{array}{l}\text { Canopy } \\
\text { Height } \\
\text { (m) }\end{array}$ & Vegetation Community & Management & $\left(\mathrm{m}^{2} \mathrm{~m}^{-2}\right)$ & $\begin{array}{l}\text { Climatic } \\
\text { Annual } \\
\text { Precipitation } \\
(\mathrm{mm})\end{array}$ & $\begin{array}{c}\text { Mean } \\
\text { Growing } \\
\text { Season } \\
\text { Temperature }^{\mathrm{a}} \\
\left({ }^{\circ} \mathrm{C}\right)\end{array}$ & $\begin{array}{l}\text { Mean } \\
\text { Growing } \\
\text { Season } \\
\text { VPD }^{a} \\
(\mathrm{kPa})\end{array}$ \\
\hline $\begin{array}{l}\text { Howland } \\
\text { Logged } \\
\text { (US-Ho3) }\end{array}$ & $\begin{array}{l}45.207 \\
-68.725\end{array}$ & $2006-2008$ & \multirow[t]{3}{*}{$20^{b}$} & \multirow{3}{*}{$\begin{array}{l}\text { Dominated by red spruce (Picea } \\
\text { rubens) and eastern hemlock (Tsuga } \\
\text { canadensis). Also contains balsam fir } \\
\text { (Abies balsamea), white pine (Pinus } \\
\text { strobus), white cedar (Thuja } \\
\text { occidentalis), red maple (Acer rubrum), } \\
\text { and paper birch (Betula papyrifera) }{ }^{c} \text {. }\end{array}$} & $\begin{array}{l}\text { Selected } \\
\text { logging and } \\
\text { harvest } \\
(2001)^{b}\end{array}$ & 2.1 to $\sim 4^{\mathrm{e}}$ & \multirow[t]{3}{*}{$1000^{b}$} & 16.7 & 0.83 \\
\hline $\begin{array}{l}\text { Howland } \\
\text { Reference } \\
\text { (US-Ho1) }\end{array}$ & $\begin{array}{l}45.204 \\
-68.740\end{array}$ & $2006-2008$ & & & $\begin{array}{l}\text { Minimal } \\
\text { disturbance } \\
\text { since } 1900 \mathrm{~s}^{\mathrm{d}}\end{array}$ & $\sim 6^{b}$ & & 17.6 & 0.87 \\
\hline $\begin{array}{l}\text { Howland } \\
\text { N Fertilized } \\
\text { (US-Ho2) }\end{array}$ & $\begin{array}{l}45.209 \\
-68.747\end{array}$ & $2006-2009$ & & & $\begin{array}{l}\text { N addition } \\
(2001-2005)^{d, e}\end{array}$ & $\sim 6^{b}$ & & 16.5 & 0.82 \\
\hline $\begin{array}{l}\text { Mead } \\
\text { Irrigated } \\
\text { Maize } \\
\text { (US-Ne1) }\end{array}$ & $\begin{array}{l}41.165 \\
-96.476\end{array}$ & 2001-2012 & $2.9^{\dagger}$ & Maize (Zea mays) & $\begin{array}{l}\text { Center-pivot } \\
\text { irrigation }^{f}\end{array}$ & $5.7^{\mathrm{e}}$ & \multirow[t]{5}{*}{$887^{\dagger}$} & 27.0 & 1.33 \\
\hline $\begin{array}{l}\text { Mead } \\
\text { Irrigated } \\
\text { Rotation: } \\
\text { Maize } \\
\text { (US-Ne2) }\end{array}$ & \multirow[t]{2}{*}{$\begin{array}{l}41.164 \\
-96.470\end{array}$} & $\begin{array}{l}2001,2003 \\
2005,2007 \\
2009-2012\end{array}$ & $2.9^{\mathrm{e}}$ & Maize (Z. mays) & \multirow[t]{2}{*}{$\begin{array}{l}\text { Center-pivot } \\
\text { irrigation }^{\dagger}\end{array}$} & $5.3^{e}$ & & \multirow[t]{2}{*}{26.2} & \multirow[t]{2}{*}{1.14} \\
\hline $\begin{array}{l}\text { Mead } \\
\text { Irrigated } \\
\text { Rotation: } \\
\text { Soybean } \\
\text { (US-Ne2) }\end{array}$ & & $\begin{array}{l}2002,2004, \\
2006,2008\end{array}$ & $1.0^{\mathrm{e}}$ & Soybean (Glycine max) & & $4.9^{\mathrm{e}}$ & & & \\
\hline $\begin{array}{l}\text { Mead } \\
\text { Rainfed } \\
\text { Rotation: } \\
\text { Maize } \\
\text { (US-Ne3) }\end{array}$ & \multirow[t]{2}{*}{$\begin{array}{l}41.179 \\
-96.439\end{array}$} & $\begin{array}{l}2001,2003 \\
2005,2007 \\
2009,2011\end{array}$ & $2.6^{\mathrm{e}}$ & Maize (Z. mays) & \multirow[t]{2}{*}{$\begin{array}{l}\text { Naturally } \\
\text { rainfed }^{g}\end{array}$} & $4.2^{\mathrm{e}}$ & & \multirow[t]{2}{*}{26.7} & \multirow[t]{2}{*}{1.39} \\
\hline $\begin{array}{l}\text { Mead } \\
\text { Rainfed } \\
\text { Rotation: } \\
\text { Soybean } \\
\text { (US-Ne3) }\end{array}$ & & $\begin{array}{l}2002,2004 \\
2006,2008 \\
2010,2012\end{array}$ & $0.9^{\mathrm{e}}$ & Soybean (G. max) & & $3.8^{\mathrm{e}}$ & & & \\
\hline $\begin{array}{l}\text { Morgan } \\
\text { Monroe } \\
\text { (US-MMS) }\end{array}$ & $\begin{array}{l}39.323 \\
-86.413\end{array}$ & $2007-2010$ & $27^{h}$ & $\begin{array}{l}\text { Dominated by sugar maple ( } A \text {. } \\
\text { saccharum), tulip poplar (Liriodendron } \\
\text { tulipifera), sassafras (Sassafras } \\
\text { albidum), white oak (Quercus alba), }\end{array}$ & None & $5^{1}$ & $1012^{]}$ & 24.3 & 1.12 \\
\hline
\end{tabular}




\begin{tabular}{|c|c|c|c|c|c|c|c|c|c|}
\hline & & & & and black oak (Q. nigra) ${ }^{n}$. & & & & & \\
\hline $\begin{array}{l}\text { UMBS } \\
\text { (US-UMB) }\end{array}$ & $\begin{array}{l}45.559 \\
-84.713\end{array}$ & $2007-2011$ & $22^{k}$ & $\begin{array}{l}\text { Dominated by bigtooth aspen (Populus } \\
\text { grandidentata) with red oak ( } Q \text {. rubra), } \\
\text { red maple }(A \text {. rubrum), and white pine } \\
\text { ( } P \text {. strobus), as co-dominants. Also } \\
\text { contains trembling aspen }(P . \\
\text { tremuloides), white birch ( } B \text {. } \\
\text { papyrifera), sugar maple ( } A \text {. } \\
\text { saccharum), red pine ( } P \text {. resinosa), } \\
\text { and American beech (Fagus } \\
\text { grandifolia). }{ }^{\mathrm{k}}\end{array}$ & None & $\sim 3.5^{\mathrm{K}}$ & $817^{\mathrm{k}}$ & 21.2 & 1.05 \\
\hline
\end{tabular}

$157{ }^{\mathrm{a}}$ Values calculated from AmeriFlux data, ${ }^{\mathrm{b}} \mathrm{Scott}$ et al., 2004, ${ }^{\mathrm{C}}$ Hollinger et al., 2004, ${ }^{\mathrm{d}}$ AmeriFlux website, ${ }^{\mathrm{e}}$ personal communication

158 with site investigator, ${ }^{\mathrm{f}}$ Yan et al., 2012, ${ }^{\mathrm{g}}$ Verma et al., 2005, ${ }^{\mathrm{h}}$ Dragoni et al., 2011, ${ }^{\mathrm{i}}$ Oliphant et al., 2011, ${ }^{\mathrm{j}} \mathrm{Curtis}$ et al., 2002, ${ }^{\mathrm{k}}$ Gough et

159 al., 2013 


\subsection{Definition of Analysis Period}

To determine the maximum effect of diffuse light on GPP, we limited our period of

162 analysis to the portion of the year when ecosystems are most productive. We used a carbon-flux

163 phenology approach, where NEE is the defining variable for phenological transitions and the

164 peak-growing season is the time period when NEE is at its maximum magnitude (Garrity et al.,

165 2011). To do this, we first calculated 5-day NEE means for each site and year. Climate,

166 vegetation composition, and inter-annual weather variability lead to phenological variation

167 among sites (Richardson et al., 2013). Therefore, we adjusted our definition for the beginning

168 and end of the peak-growing season to uniformly capture a representative portion of the NEE

169 peak across sites and years. We defined the start of the growing season as the first day when the

170 5-day NEE average was within $90 \%$ of the year's fourth highest 5-day NEE average. The

171 fourth-highest value was used to account for any extreme NEE values that may have occurred

172 because of anomalous weather conditions. We set the end of season as the last day within $75 \%$

173 of the year's fourth-highest 5-day NEE average. The cutoff for the start of the peak-growing

174 season is higher than the cutoff for the end of the season because canopy leaf-out and growth

175 initiation typically occur quickly in seasonal sites, whereas canopy phenological changes are

176 slower at the end of the season. While this approach cannot detect the exact beginning and end

177 of the season, the criteria we used provide a uniform method for defining the period during

178 which plants were at full seasonal growth and activity at our sites. We included only daytime

179 values by excluding points with total PAR values $<20 \mu \mathrm{mol} \mathrm{m} \mathrm{m}^{-2} \mathrm{~s}^{-1}$, assuming such low radiation

180 levels are characteristic for nighttime. 


\subsection{Data Analysis}

For each site, we combined all available peak-growing season daytime data and removed

183 observations with negative measurements of diffuse PAR, direct PAR, or GPP, as these were

184 likely sensor errors or marginal weather conditions (e.g., rain events). We also excluded data

185 points with missing air temperature and VPD. We divided the remaining data into nine

186 categorical groups based on solar zenith angle and the time of observation. We chose to bin by

187 zenith angle to account for the effect of the sun's position on the amount of direct and diffuse

188 PAR above a canopy, differences in radiation penetration through the canopy, and changes in

189 plant hydraulics throughout the day. Zenith angle was calculated as the following:

$$
\cos \varphi=\sin \phi \sin \delta+\cos \phi \cos \delta \cos \left[15\left(t-t_{0}\right)\right]
$$

191 where $\varphi$ is the zenith angle, $\phi$ is the latitude, $\delta$ is the solar declination angle, $t$ is time, and $t_{0}$ is the

192 time of solar noon (Campbell and Norman, 1998). Given the latitudes of the sites, we defined

193 mornings to begin at zenith angles between $76-100^{\circ}$, noon to occur at the minimum calculated

194 zenith angles of $16-30^{\circ}$, and the end of daylight to occur around $76-100^{\circ}$.

195 The effect of diffuse PAR on GPP may depend on total light conditions. For example,

196 little scattering occurs under clear skies, which results in low diffuse and high direct PAR levels.

197 As a result, small increases in diffuse PAR are unlikely to have a strong impact on canopy

198 photosynthesis due to large amounts of direct PAR available for photosynthesis. If direct PAR

199 levels are low, however, such as on cloudy days or during the morning and evening, the increase

200 in diffuse PAR will have a larger effect because canopy leaves are below light-saturation. To

201 calculate direct PAR, we subtracted the observed diffuse PAR from the observed total PAR.

202 Because GPP and PAR are known to have a strong relationship that can be empirically described 
203 by a rectangular hyperbola, we used the non-linear regression function in the $\mathrm{R}$ program $(\mathrm{R}$

204 Development Core Team, 2012) to fit the following relationship:

$$
G P P_{\text {fitted }}=\left(\alpha \gamma P A R_{\text {dir }}\right) /\left(\gamma+\alpha P A R_{\text {dir }}\right)
$$

206 where $G P P_{\text {fitted }}$ is the value of GPP predicted by total PAR using a rectangular hyperbola model

207 (Eq. 2), $\alpha$ is the canopy quantum efficiency, $\gamma$ is the canopy photosynthetic potential, and $P A R_{d i r}$

208 is direct PAR (Gu et al., 2002). The $\alpha$ and $\gamma$ are the fitted parameters and are solved iteratively.

209 We used the initial conditions of $0.044 \mu \mathrm{mol} \mathrm{CO} 2$ per $\mu \mathrm{mol}$ photons and $23.7 \mu \mathrm{mol} \mathrm{CO} \mathrm{m}^{-2} \mathrm{~s}^{-1}$

210 for $\alpha$ and $\gamma$, respectively (Ruimy et al., 1995). The resulting empirical relationships for each site

211 are presented in Appendix 1.

212 To remove the confounding effect of direct PAR, we first calculated the residuals

213 between observed GPP and $G P P_{\text {fitted }}$. We then compared those residuals against diffuse PAR for

214 ten sites and nine zenith angle bins. For each zenith angle category, we estimated the variation

215 in GPP residuals that can be explained by diffuse PAR alone using the following simple linear

216 regression:

$$
G P P_{r}=G P P-G P P_{\text {fitted }}=\beta_{0}+\beta_{1} P A R_{\text {diff }}+\varepsilon
$$

218 and a combination of diffuse PAR, VPD, and air temperature using the following multiple linear 219 regression:

$$
G P P_{r}=G P P-G P P_{\text {fitted }}=\beta_{0}+\beta_{1} P A R_{\text {diff }}+\beta_{2} V P D+\beta_{3} T_{a}+\varepsilon
$$

221 where $G P P_{r}$ represents the residuals between the observed GPP and $G P P_{\text {fitted }}$ and $P A R_{\text {diff }}$ is

222 diffuse PAR. $T_{a}$ is air temperature measured at the eddy covariance tower and $\beta_{0}, \beta_{1}, \beta_{2}$ and $\beta_{3}$

223 are the fitted parameters estimating the model intercept and the linear slopes of the effects of

224 diffuse PAR, VPD, and air temperature at each solar zenith bin, respectively. The $\varepsilon$ is the error 225 term. 
ANOVA comparisons between the simple (diffuse PAR only) and multiple linear

227 regressions (including VPD and air temperature) showed that the multiple linear regression

228 model (Eq. 4) was significantly better $(\mathrm{p}<0.05)$ than the simple regression model, with the

229 exception of nine site/bin combinations. We did not include interactions in the multiple linear

230 regression because ANOVA tests indicated that the interaction terms did not improve the model

231 consistently, and improvements to the residual sum of squares averaged only $3.5 \%$ in cases

232 where interaction terms were significant. We also accounted for multiple testing over solar

233 zenith angle bins and different sites by using the Bonferroni correction to calculate a new critical

234 p-value. Light-response curves could not be fit to all scenarios, reducing the final number of

235 comparisons to 83. Thus, for the simple and multiple linear regression comparisons, we consider

236 a relationship significant if $\mathrm{p}<6.02 \times 10^{-4}(=0.05 / 83)$.

\section{3. Results}

\section{$238 \quad 3.1$ Relationship between diffuse PAR and GPP}

239 We found significant positive relationships between diffuse PAR and $G P P_{r}$ throughout

240 the day, except in a few cases where diffuse PAR was not a significant predictor of $G P P_{r}$ (Fig. 1,

241 Fig. 2, black bars). Exceptions to these relationships occurred mainly at the Mead crop sites

242 during mid-day and to a lesser extent at the UMBS forest during early mornings and late

243 afternoons (Fig. 2, black bars). In addition, a rectangular hyperbola could not be fit to the direct

244 PAR and GPP data in the afternoon at large zenith angles at the Mead sites and Morgan Monroe

245 (Appendix 1). Overall, the linear fits between diffuse PAR and $G P P_{r}$ indicate that across sites

246 and zenith angles, diffuse PAR explains 3-22\% of variation in $G P P_{r}$ in the morning and 3-41\%

247 of variation in $G P P_{r}$ in the afternoon (Fig. 2, black bars). 
249 forests and crop sites (Fig. 2, black bars). At the deciduous broadleaf and mixed conifer forests, 250 diffuse PAR accounts for more of the variance in $G P P_{r}$ at the smallest zenith angle bins (mid251 day) and less at larger zenith angles in the early mornings and late afternoons (Fig. 2a-e, black 252 bars). However, the opposite pattern occurs at the Mead crop sites, where more of the variance 253 in $G P P_{r}$ is associated with diffuse PAR at larger zenith angles (Fig. 2f-j, black bars). Diffuse 254 PAR accounted for the largest portion of $G P P_{r}$ variance at crop sites during afternoon zenith 255 angles of $61-75^{\circ}$, corresponding to approximately 17:00-18:00 standard time. 
Zenith Angles: $16-30^{\circ}$
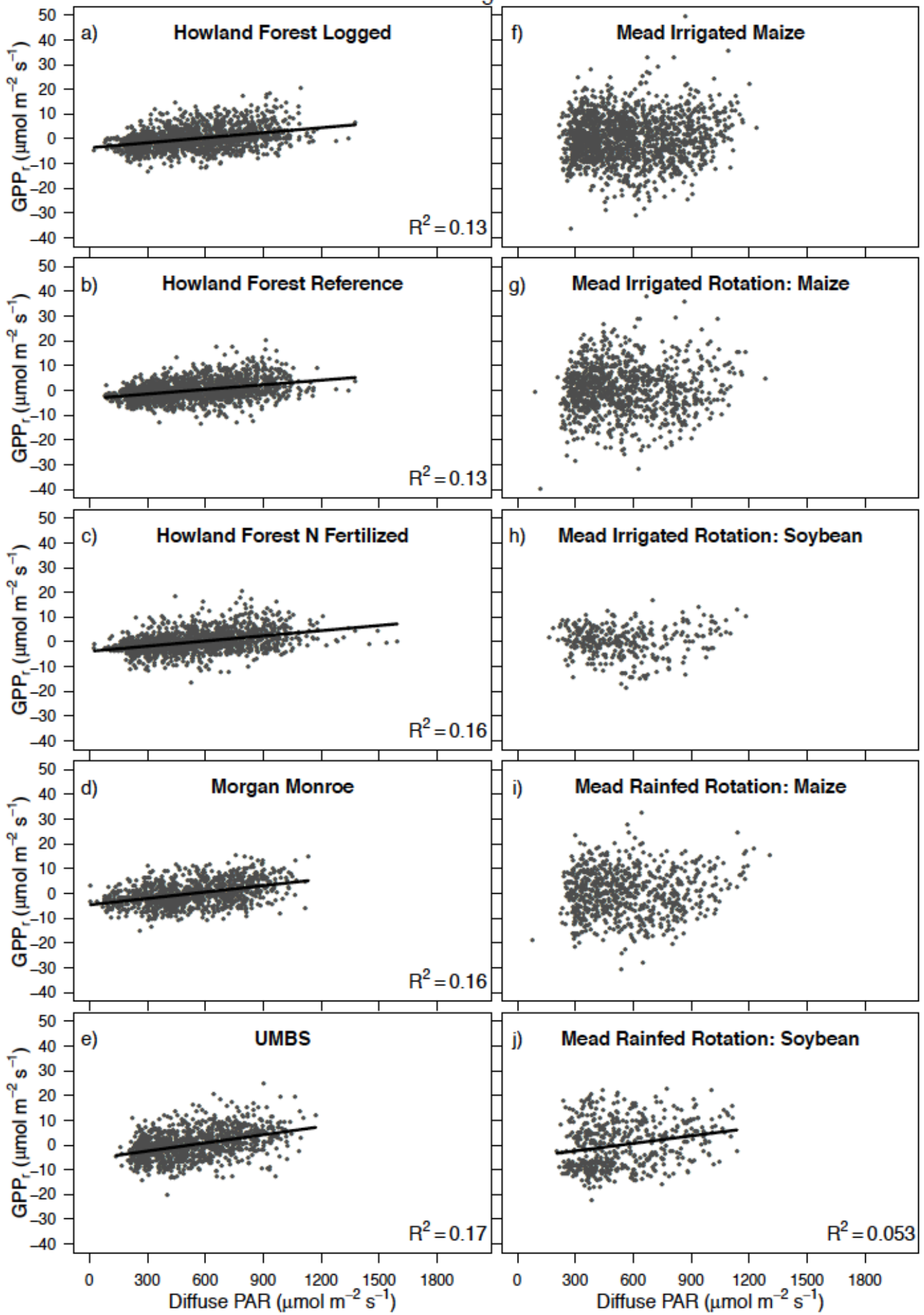

Fig 1. Simple linear regressions (Eq. 3) between diffuse PAR and $G P P_{r}$ for observations around 10:00 14:00 standard time (zenith angles from $16-30^{\circ}$, other zenith angle bins not shown). Regression lines are only plotted for models with $p<6.02 \times 10^{-4}$ (Bonferroni-corrected critical value). 

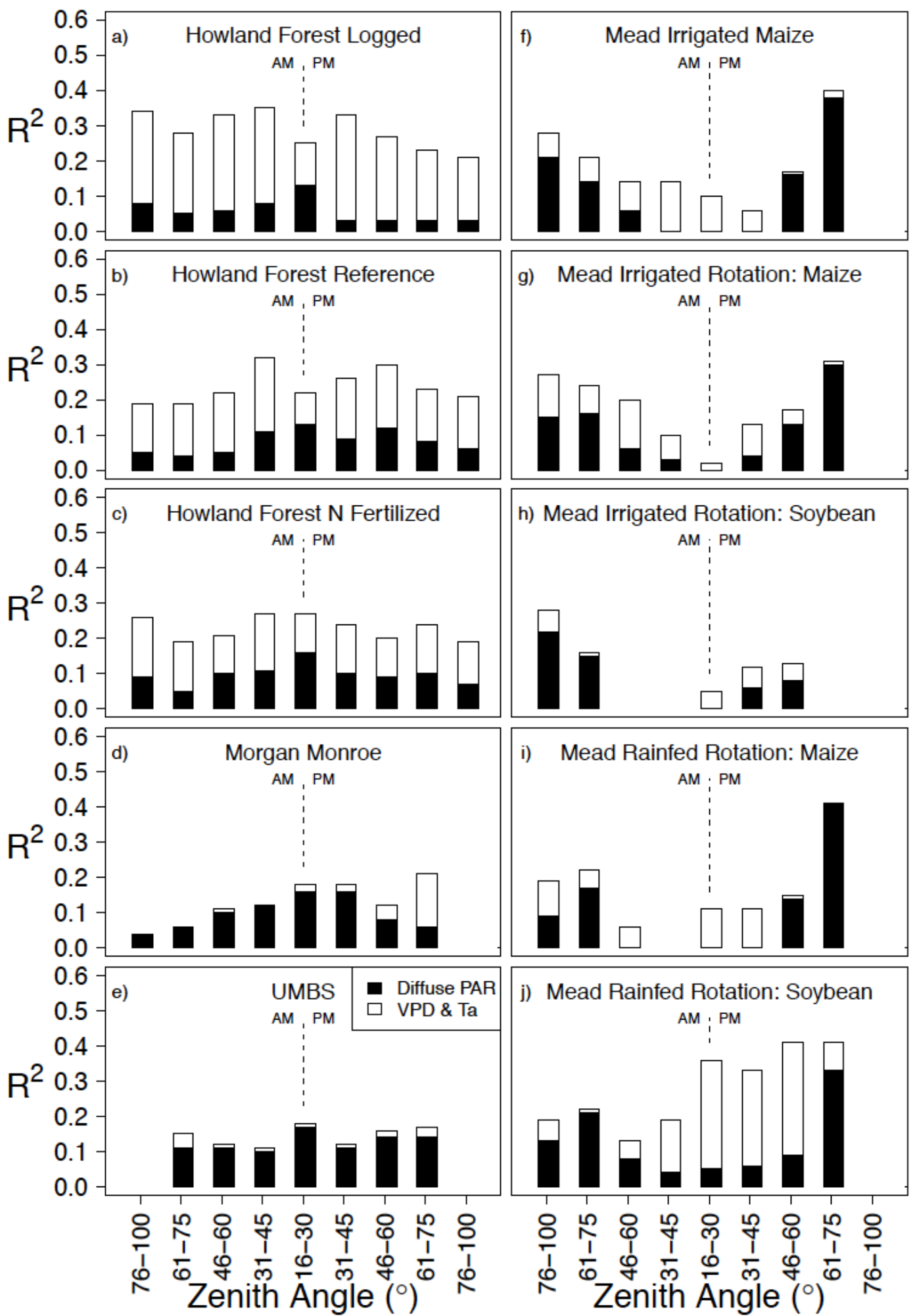

Fig 2: Proportions of variation in $G P P_{r}$ explained by environmental variables. Solid bars represent $\mathrm{R}^{2}$ values from simple linear regressions that include only the effect of diffuse PAR (Eq. 3). The total height of the bars (solid and white together) represents the $R^{2}$ from multiple linear regressions that include effects of air temperature ( $T_{a}$ ) and vapor pressure deficit (VPD) with diffuse PAR (Eq. 4). Only $R^{2}$ values with $p<6.02 \times 10^{-4}$ (Bonferroni-corrected critical value) are plotted. The minimum calculated zenith angle for these sites was $\sim 16^{\circ}$. 
Concomitant with changes in the partitioning of PAR into direct and diffuse streams,

258 clouds and aerosols change surface VPD and air temperature. These two environmental factors

259 influence stomatal conductance and photosynthesis, and thus affect rates of ecosystem GPP.

260 When including the effects of these two variables on $G P P_{r}$ with diffuse PAR (Eq. 4), the amount

261 of variation in $G P P_{r}$ explained increases up to an additional $31 \%$ during mornings and up to $32 \%$

262 during afternoons (Fig 2, white bars). This increase with VPD and air temperature is greatest

263 across the most zenith angles at the Howland sites, where the multiple linear regression increases

264 explanatory power of $G P P_{r}$ by an additional $9-27 \%$ and $11-30 \%$ in the mornings and afternoons,

265 respectively. VPD and air temperature also account for a relatively larger fraction of the

266 variation of Mead Rainfed Rotation: Soybean $G P P_{r}$ during the mid-day. Although we expected

267 an increase in explanatory power with more variables in the regression, the increase in the

268 explanation of $G P P_{r}$ with the addition of these correlated environmental variables is small for the

269 deciduous forests (Morgan Monroe and UMBS). This suggests that the effect of diffuse PAR at

270 the deciduous forests is due to changes in light availability and not from indirect effects driven

271 by the cross-correlation between diffuse PAR and other environmental conditions. Overall, the

272 multiple linear regressions indicate that diffuse PAR is a significant predictor of $G P P_{r}$ (except

273 for the sites and zenith angle bins noted in Table 2). In addition, VPD and air temperature could

274 not account for significant amounts of $G P P_{r}$ variation under some conditions (Table 2). 
Table 2: Parameter estimate values from relationships between $G P P_{r}$ and diffuse PAR, vapor pressure deficit (VPD), and air temperature ( $\left.T_{a}\right)$. All $\beta_{i}$ estimate values (Eq. 4) have $\mathrm{p}<6.02 \times 10^{-4}$ (Bonferroni-corrected critical value), except for those designated as NS.

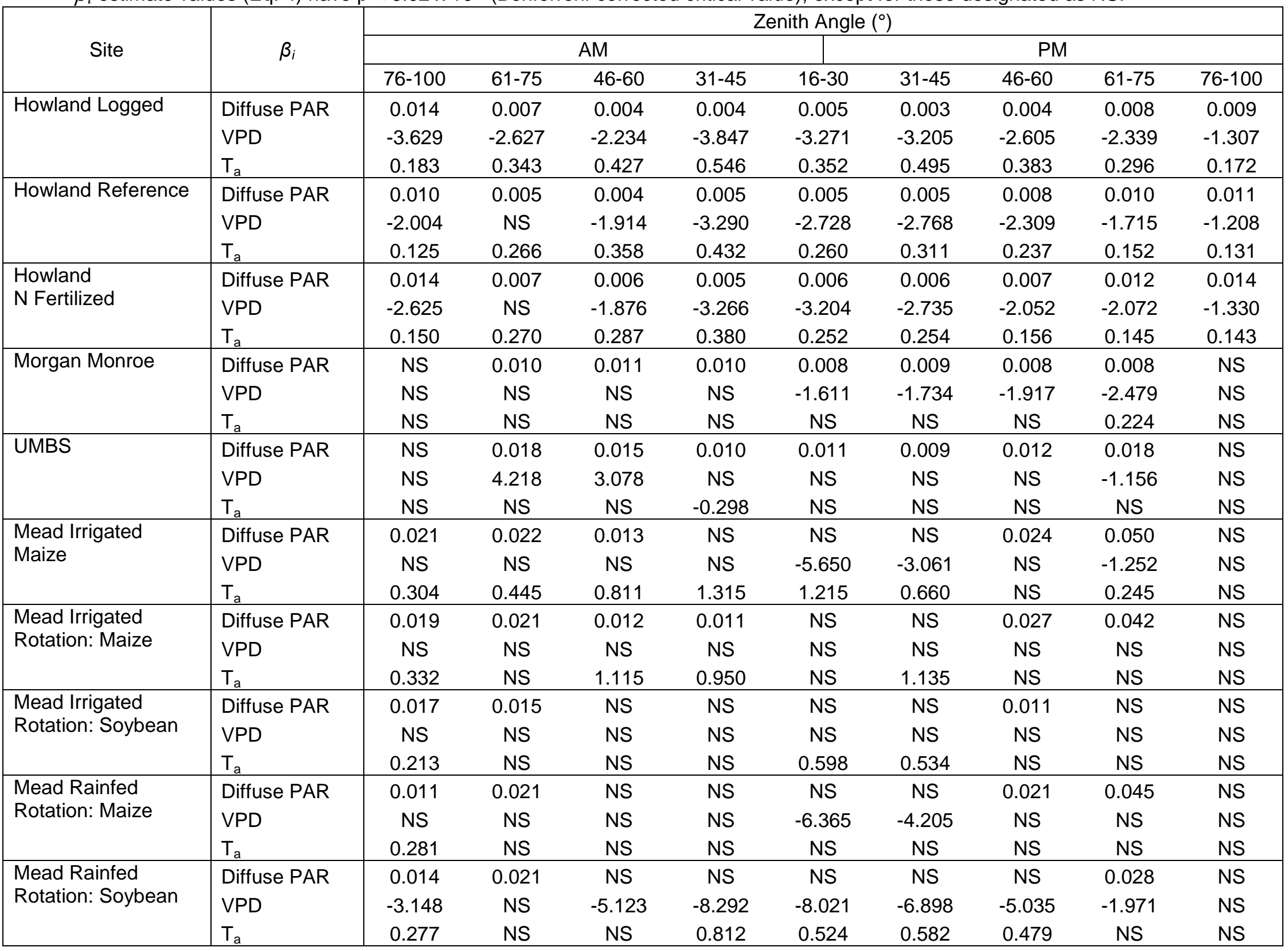




\subsection{Magnitude of the effects of diffuse PAR on GPPr}

278

279

280

281

282

283

284

285

286

287

288

289

290

291

292

293

294

295

296

297

Howland Forest Reference, Morgan Monroe, and UMBS have not undergone any experimental manipulation (e.g., selective logging, $\mathrm{N}$ addition). At these sites, the sign of the significant parameter estimates indicate that in mornings and afternoons, $G P P_{r}$ increased with diffuse PAR (Table 2). The predicted increases in $G P P_{r}$ in the morning were calculated to be 0.004-0.010, 0.008-0.011, and 0.010-0.018 $\mu \mathrm{mol} \mathrm{CO} 2$ per $\mu \mathrm{mol}$ photons of diffuse PAR at Howland Forest Reference, Morgan Monroe, and UMBS, respectively (Fig. 3). In the afternoon, the increases in $G P P_{r}$ were similar in magnitude, and ranged from 0.005-0.011, 0.008-0.009, and 0.009-0.018 $\mu \mathrm{mol} \mathrm{CO}_{2}$ per $\mu \mathrm{mol}$ photons of diffuse PAR at Howland Forest Reference, Morgan Monroe, and UMBS, respectively (Fig. 3).

The effect of diffuse PAR on rates of $G P P_{r}$ varied among forest sites. UMBS had the largest increases in $G P P_{r}$ with increases in diffuse PAR, and Howland Forest Reference had the smallest increases in $G P P_{r}$. In addition, the calculated increases in $G P P_{r}$ with diffuse PAR appear to depend on zenith angle at two of the sites. At UMBS, the influence of diffuse PAR on $G P P_{r}$ is greatest in the early morning and late afternoon (zenith angles $61-75^{\circ}$ ) and decreases at

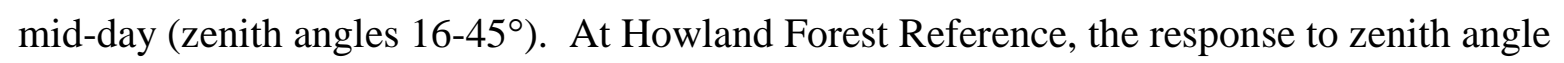
differs and the influence of diffuse PAR on $G P P_{r}$ generally increases as the day continues and is highest in the late afternoon (zenith angles $76-100^{\circ}$ ). However, at Morgan Monroe, the influence of diffuse PAR on $G P P_{r}$ did not vary with zenith angle. When we compare across these ecosystems, deciduous forests (UMBS, Morgan Monroe) appear to differ from the mixed conifer forest, particularly in the morning, with differences diminishing in the afternoon. 


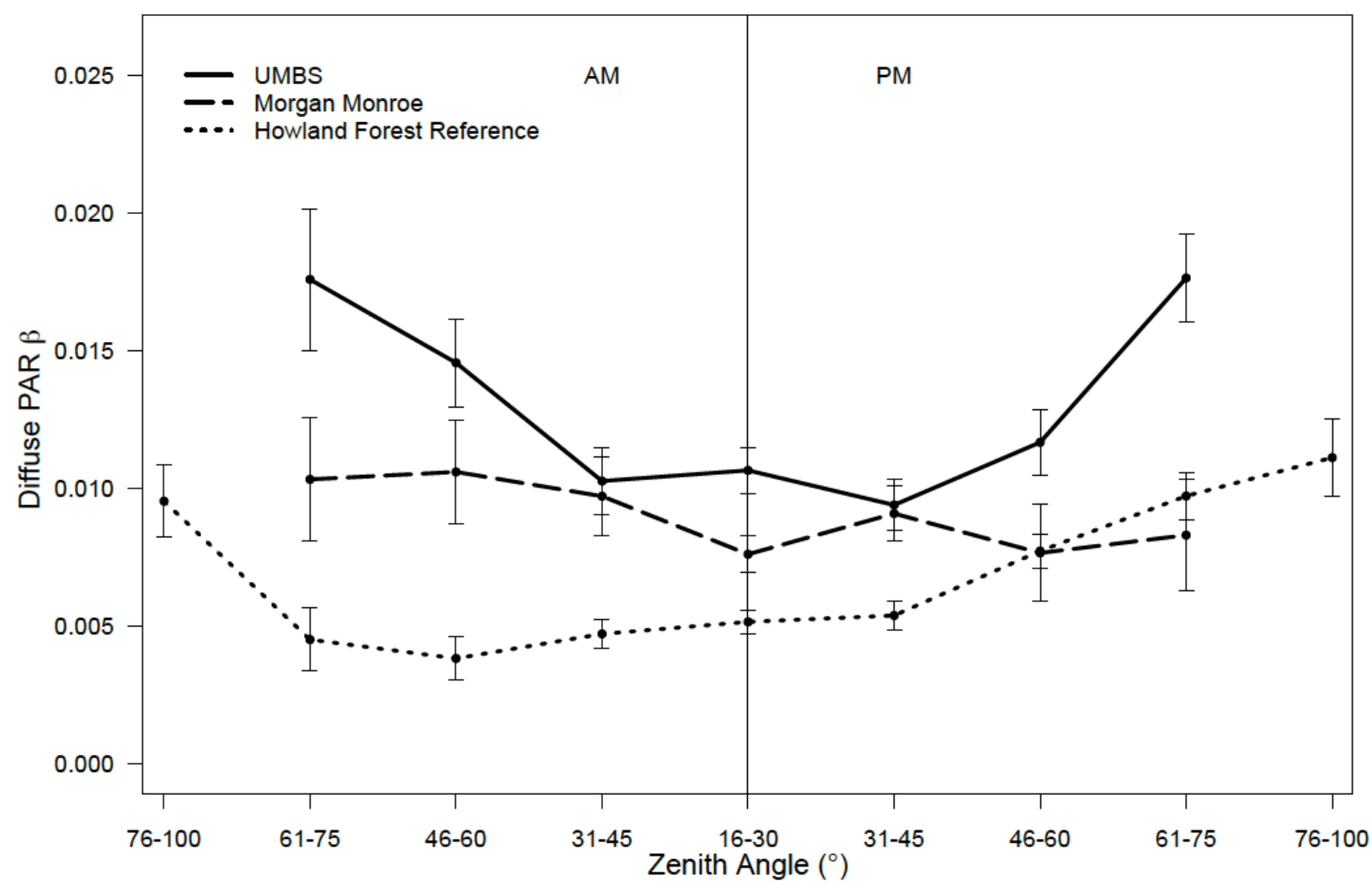

Fig 3. Diurnal patterns in diffuse PAR $\beta$ estimates for unmanaged forests across zenith angles from a multiple linear regression that includes VPD and air temperature as covariates (Eq. 4). Error bars indicate

one standard error. Only $\beta$ estimates with $p<6.02 \times 10^{-4}$ (Bonferroni-corrected critical value) are plotted.

At Howland Forest, one site underwent selective logging while a second site was

300 fertilized with $18 \mathrm{~kg} \mathrm{~N} / \mathrm{ha}$ on a 21-hectare plot centered around the eddy covariance tower in five

301 to six applications per growing season from 2001-2005 (David Dail, personal communication,

302 2013). Analysis of data at these manipulated sites indicates that the magnitude of increase in

$303 G P P_{r}$ with diffuse PAR was similar to that of the un-manipulated Howland forest (Fig. 4).

304 Differences among forest treatments are not apparent in the morning. In the afternoon, however,

305 we observe a trend where diffuse PAR leads to the biggest $G P P_{r}$ increase in the forest fertilized

306 with $\mathrm{N}$ and the smallest change in $G P P_{r}$ in the forest that has been selectively logged. 


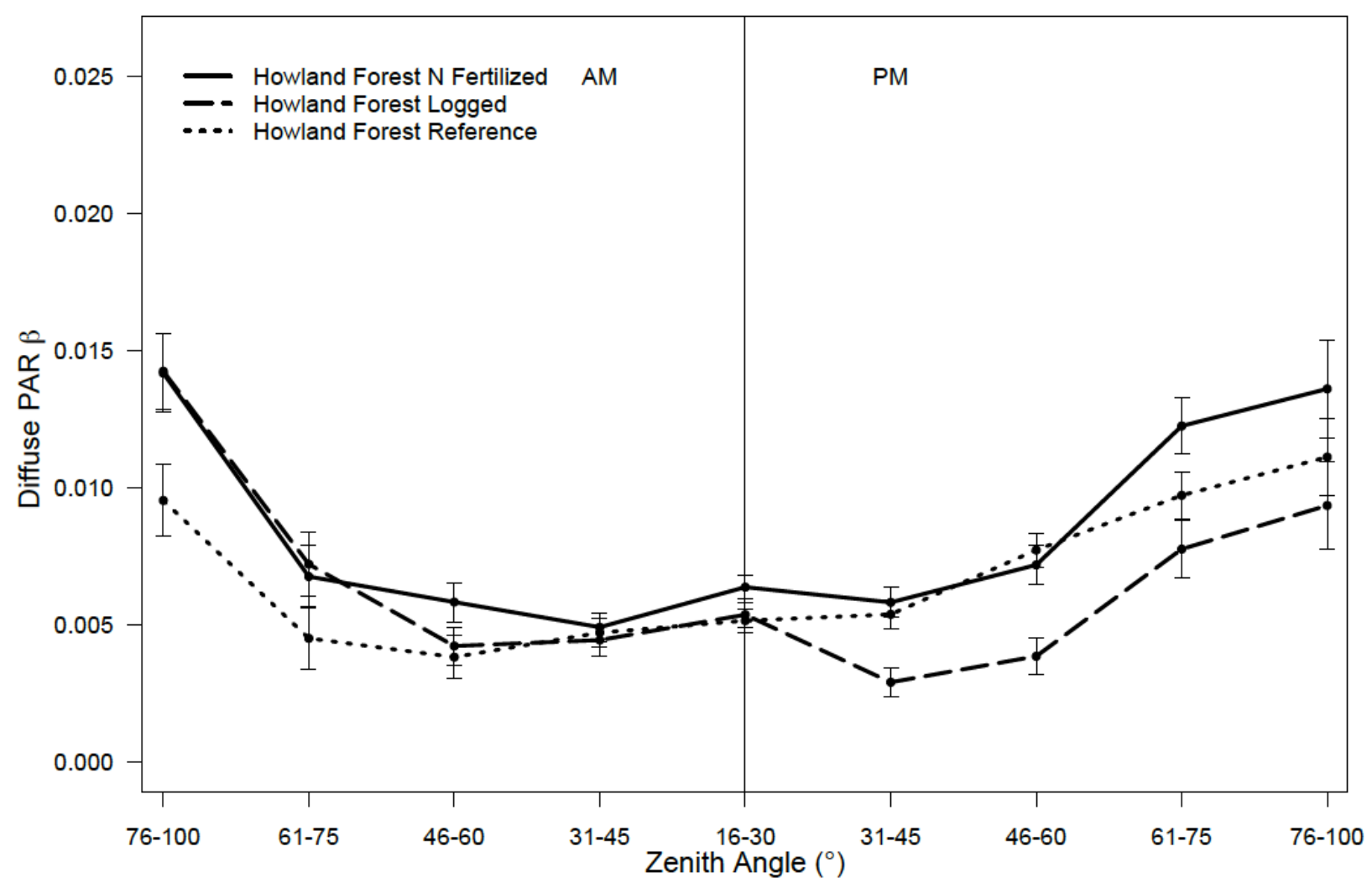

Fig 4: Diurnal patterns in diffuse PAR $\beta$ estimate values for Howland Forest sites across zenith angles from a multiple linear regression that includes VPD and air temperature as covariates (Eq. 4). Error bars indicate one standard error. Only values with $p<6.02 \times 10^{-4}$ (Bonferroni-corrected critical value) are plotted.

At the Mead Irrigated Rotation and Mead Rainfed Rotation sites, soybean and maize are

309 planted in different years, allowing us to examine variations in the effect of diffuse PAR on

$310 G P P_{r}$ between crop types (Fig. 5). The increases in $G P P_{r}$ for maize were calculated to be $0.011-$

$3110.022 \mu \mathrm{mol} \mathrm{CO} 2$ per $\mu \mathrm{mol}$ photons in the morning and $0.021-0.050 \mu \mathrm{mol} \mathrm{CO}_{2}$ per $\mu \mathrm{mol}$ photons

312 in the afternoon. For soybean, the increases in $G P P_{r}$ in the morning were $0.014-0.021 \mu \mathrm{mol} \mathrm{CO}_{2}$

313 per $\mu \mathrm{mol}$ photons and in the afternoon were $0.011-0.028 \mu \mathrm{mol} \mathrm{CO} 2$ per $\mu \mathrm{mol}$ photons. Diffuse

314 PAR led to increases in $G P P_{r}$ at large zenith angles, but had no effect on $G P P_{r}$ at small zenith

315 angles for both crop species (values are only plotted in Fig. 5 if they are significant). In addition,

316 we observed no difference in the magnitude of the effect of diffuse PAR on $G P P_{r}$ between

317 soybean and maize in the morning. However, we did observe a greater effect of diffuse PAR on 
$318 G P P_{r}$ for maize than soybean in the afternoon for zenith angles $46-75^{\circ}$. Irrigation did not appear

319 to influence the magnitude of the diffuse PAR effect on $G P P_{r}$.

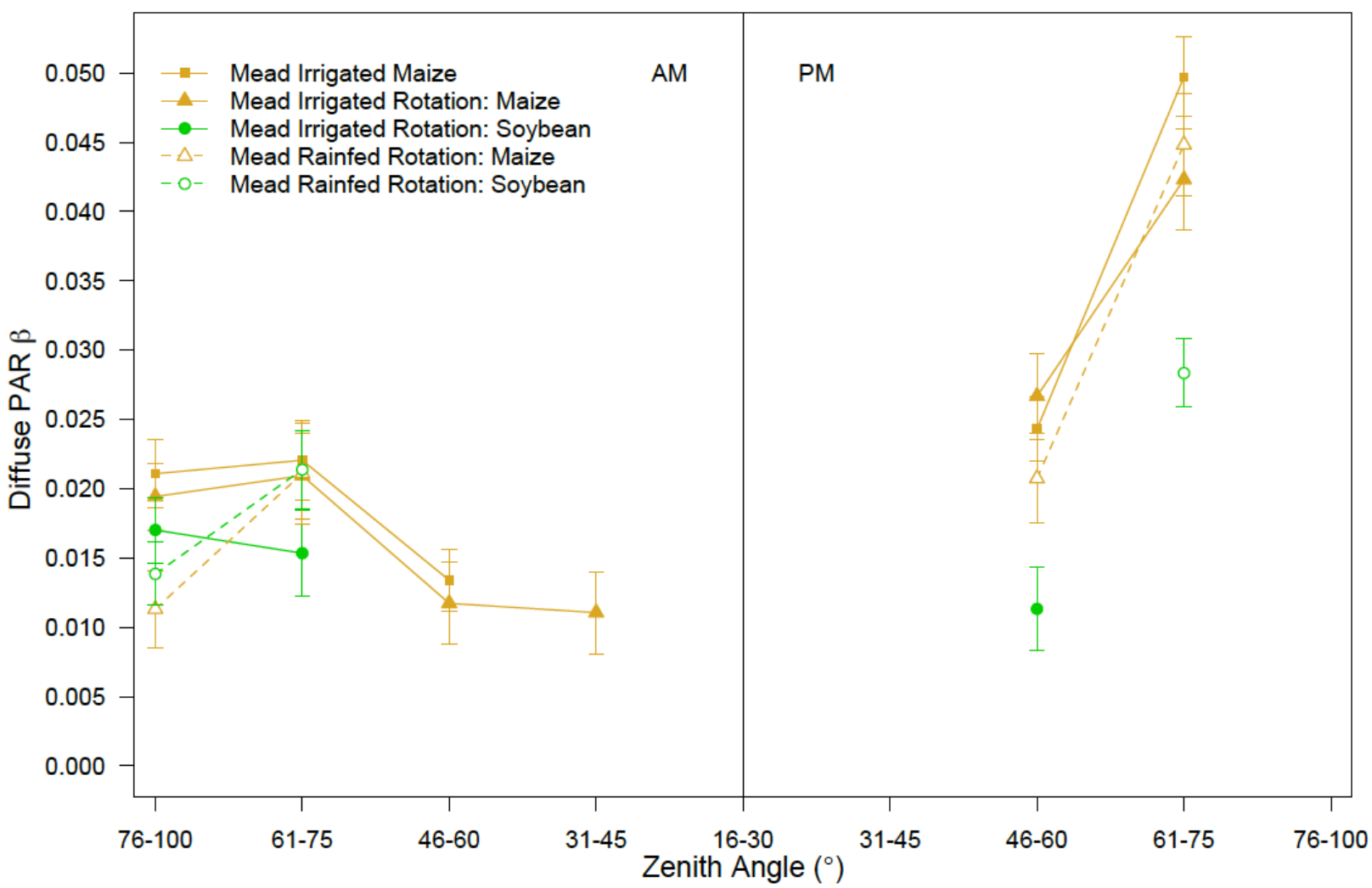

Fig 5: Diurnal patterns in diffuse PAR $\beta$ estimate values for Mead crop sites across zenith angles from a multiple linear regression that includes VPD and air temperature as covariates (Eq. 4). Error bars indicate one standard error. Only $\beta$ values with $p<6.02 \times 10^{-4}$ (Bonferroni-corrected critical value) are plotted.

\section{4. Discussion}

Diffuse light influences Earth's climate by changing the amount and character of light

323 available for photosynthesis, and thus, indirectly controls atmospheric $\mathrm{CO}_{2}$ (Mercado et al.,

324 2009). Depending on future anthropogenic emissions and their effects on atmospheric aerosols

325 and clouds, the influence of diffuse light on the terrestrial carbon sink may increase. A more

326 quantitative and mechanistic understanding of the link between diffuse light and land carbon

327 uptake in different ecosystems would allow us to model how changes in diffuse light influence 
atmospheric and terrestrial carbon stocks, particularly as land-use change (e.g., deforestation,

329 afforestation, and conversion of natural systems to cropland) continues (Arora and Boer, 2010).

330 Past research has identified a positive correlation between diffuse light and ecosystem

331 carbon uptake. However, this result may be due to a cross-correlation with total light

332 availability, where diffuse light could more strongly influence photosynthesis when total light

333 levels are low on overcast days as compared to high light levels on clear days (Gu et al., 1999b;

334 Oliphant et al., 2011; Zhang et al., 2010). The method we use in this paper addresses this

335 confounding factor by removing the effect of direct light on ecosystem carbon uptake before

336 calculating the rate of additional carbon uptake from diffuse light. Importantly, we tested for this

337 potential independent effect using only direct field measurements of diffuse light, as opposed to

338 deriving diffuse light levels with radiation partitioning models that make assumptions about

339 aerosol and cloud conditions over terrestrial ecosystems. Our analysis of ten temperate

340 ecosystems indicates that diffuse PAR correlates positively with $G P P_{r}$ and this relationship is

341 independent of direct PAR levels. Specifically, diffuse PAR independently explained up to $22 \%$

342 of the variation in $G P P_{r}$ in mornings and up to $41 \%$ of the variation in $G P P_{r}$ in afternoons.

343 Prior research shows that morning and afternoon responses to diffuse light can differ for

344 the same zenith angles (Alton et al., 2005) and that in multiple ecosystems, rates of carbon

345 enhancement vary across zenith angles (Bai et al., 2012; Zhang et al., 2010). However, to our

346 knowledge, no other studies have investigated full diurnal patterns of diffuse light enhancement.

347 We accomplished this by separating data according to zenith angle and time of day. Our results

348 indicate that in forests, the proportion of variation in $G P P_{r}$ explained by diffuse PAR (evaluated

349 through $\mathrm{R}^{2}$ ) is greatest at mid-day, and decreases as the sun moves closer to the horizon. The

350 opposite pattern occurs at crop sites, where diffuse PAR did not predict $G P P_{r}$ at small zenith 
351 angles (mid-day), but did correlate with variation in $G P P_{r}$ at larger zenith angles (morning and

352 afternoon). When we examined the magnitude of increase in $G P P_{r}$ in response to diffuse PAR

$353\left(\beta_{1}\right)$, the greatest increases were at larger zenith angles in crop sites $\left(0.028-0.050 \mu \mathrm{mol} \mathrm{CO}_{2}\right.$ per

$354 \mu \mathrm{mol}$ photons at $61-75^{\circ}$ in the afternoon). In forests, however, diffuse PAR had the strongest

355 influence $\left(\mathrm{R}^{2}\right)$ on $G P P_{r}$ at small zenith angles when the sun is overhead (mid-day), but the largest

356 carbon enhancement rate $\left(\beta_{1}\right)$ at larger zenith angles (early mornings and late afternoons) when

357 the sun is closer to the horizon.

358 In addition, some sites show a trend in an asymmetrical diurnal cycle of diffuse light

359 enhancement, most notably in the crop sites. Although increases in $G P P_{r}$ with diffuse PAR at

360 forest sites appear to be similar in magnitude throughout the day, some of the zenith angle bins

361 differed between the morning and afternoon. For example, the largest difference in carbon

362 enhancement rates from a morning zenith angle bin to the same bin in the afternoon were 0.005

$363 \mu \mathrm{mol} \mathrm{CO}_{2}$ per $\mu \mathrm{mol}$ photons for mixed conifer forests, $0.003 \mu \mathrm{mol} \mathrm{CO}_{2}$ per $\mu \mathrm{mol}$ photons for

364 deciduous forests, $0.017 \mu \mathrm{mol} \mathrm{CO}_{2}$ per $\mu \mathrm{mol}$ photons for soy, and $0.028 \mu \mathrm{mol} \mathrm{CO}_{2}$ per $\mu \mathrm{mol}$

365 photons for maize, though changes were usually within the standard error of the measurements.

366 The response of $G P P_{r}$ to diffuse light may differ in the morning and afternoon because

367 environmental conditions influencing photosynthesis also vary during the day. For example,

368 time lags between the effects of diurnal cycles of radiation and VPD on evapotranspiration

369 (Zhang et al., 2014), stronger hydraulic stresses in the afternoon (Matheny et al., 2014), and

370 morning and afternoon differences in leaf surface wetness that affect stomatal conductance

371 (Misson et al., 2005) might explain the increased importance of diffuse light in the afternoon.

372 These results can be used to evaluate ecosystem and global land surface models by testing if they

373 capture the diurnal patterns we identified. 
Our results indicate that there are ecosystem-specific responses of carbon uptake to

375 diffuse light. The observed differences between crops and forests are consistent with Niyogi et

376 al., 2004 who used measured diffuse shortwave data to show that a crop site with a corn and

377 soybean rotation was more sensitive to increases in aerosol-produced diffuse light than broadleaf

378 and mixed conifer forests. Previous studies have hypothesized that differences in canopy

379 structure among forests, grasslands, and croplands are responsible for differential responses of

380 these ecosystems to diffuse light (Gu et al., 1999a; Niyogi et al., 2004; Oliphant et al., 2011).

381 However, they have not reported site-level canopy architectural measurements to test this

382 potential modifier of land carbon uptake because they are difficult to collect and describe.

383 There are several hypotheses explaining why canopy structure may modify the effect of

384 diffuse light on ecosystem carbon uptake. Canopy gaps, which interact with the angle of

385 incident light, may influence how much light is distributed vertically through a canopy

386 (Hutchison et al., 1980). For example, on clear days in a 30-m tall tulip poplar forest, the

387 amount of radiation reaching the mid- and lower-parts of the canopy is lowest at large zenith

388 angles (Hutchison et al., 1980). The authors attributed this to the low level of total radiation and

389 reduced canopy gaps when the sun is near the horizon. Our analysis of UMBS gap fraction data

390 derived from LAI-2000 measurements shows that as gap fraction decreases, carbon uptake with

391 diffuse light increases (Fig. 6). Because gap fraction here is the ratio of below-canopy PAR to

392 above-canopy PAR, this indicates greater light extinction at larger zenith angles. Greater light

393 extinction in the canopy may increase light scattering, which could expose more leaves to diffuse

394 light. Thus, the response of GPP to diffuse light may be greater at larger zenith angles because

395 of more complete canopy participation in photosynthesis. However, more gap fraction data and

396 canopy light profiles from across sites and collected with uniform methods are needed to test this 
397 idea, particularly in crop ecosystems. This would allow us to identify why crops and forests

398 respond differently to diffuse PAR.
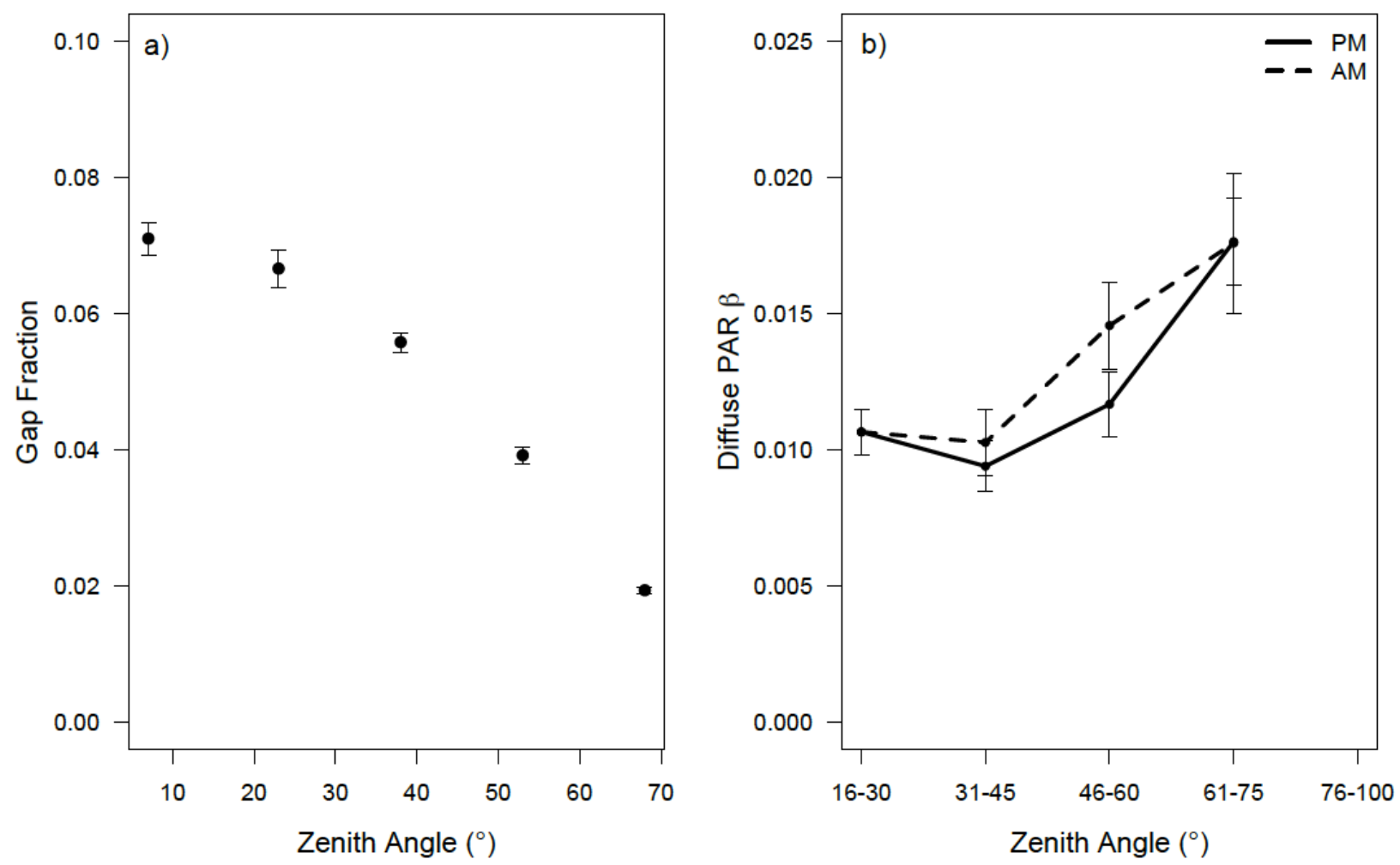

Fig. 6. The relationship at UMBS (data from 2007-2011) between a) gap fraction and zenith angle and b) diffuse PAR $\beta$ (carbon enhancement rate) and zenith angles (same data as shown in Fig. 3). Error bars indicate one standard error.

Second, the distribution of photosynthetic tissues within a canopy depends on the plant

401 community at each site and may contribute to observed differences between crops and forests.

402 Forests have more stratified layers of vegetation and are much taller than crops. This means that

403 leaf area index (LAI) in a forest is distributed over a larger volume than in crop sites. When the

404 sun is overhead, forest canopies shade leaves at lower layers and diffuse light has a greater

405 potential of reaching leaves near the bottom of the forest canopy as compared to direct light.

406 Thus, the opportunity for diffuse light to reach more leaves in the canopy is greater when the sun

407 is overhead (larger $\mathrm{R}^{2}$ ). This explanation is supported by a study in a Norway spruce forest, 
408 which showed that needles deeper in the canopy contribute more to overall net ecosystem

409 production on cloudy days than on sunny days (Urban et al., 2012). However, the relative

410 increases in GPP $\left(\beta_{1}\right)$ may be smaller than those at crop sites because forest canopies are denser,

411 which increases self-shading. On the other hand, crops are planted to minimize self-shading

412 when the sun is overhead. In addition, $\beta_{1}$ may be higher at crop sites than at forests because

413 multi-directional diffuse light at large zenith angles may reach deeper into crop canopies more

414 effectively than direct light and increase light availability for crop stems, which are more

415 photosynthetic than tree trunks.

416 Modeling studies have shown that species-dependent canopy characteristics, such as leaf

417 clumping, LAI, and leaf inclination angle can affect the influence of diffuse PAR on carbon

418 processing in ecosystems (Alton, 2008; Gu et al., 2002; Knohl and Baldocchi, 2008). This could

419 be due to the penumbral effect, which occurs when the position and types of leaves (e.g.,

420 broadleaf and conifer) alter the amount and distribution of light to lower-level leaves (Denholm,

421 1981; Way and Pearcy, 2012). Although the arrangement of leaves in tall canopies with small

422 leaves (e.g., forests) can increase shading of lower canopy leaves, it also increases the probability

423 that leaves and branches scatter light, resulting in more distribution of light in the canopy.

424 However, in shorter canopies with larger leaves (e.g., maize), there is less plant material that can

425 scatter light and these sites may be more dependent on incident diffuse light. This may explain

426 the higher carbon enhancement rates observed at crop sites compared to forests.

427 A few studies have measured how the distribution of light through plant canopies

428 changes under diffuse light, but they are limited in their ability to test the influence of canopy

429 structure on carbon enhancement from diffuse light because they have been conducted in a single

430 ecosystem (Urban et al., 2012; Williams et al., 2014). Because site-level measurements of 
431 canopy structure are difficult to obtain, support for the mechanisms through which specific

432 characteristics of canopy structure (e.g., leaf area distribution, leaf clumping) change ecosystem

433 carbon uptake under diffuse light conditions has thus far depended on model assumptions (Alton

434 et al., 2007; Knohl and Baldocchi, 2008). To test whether canopy structural differences in

435 height, canopy gaps, or leaf distribution within a canopy facilitate a diffuse light enhancement, a

436 uniform method of collecting canopy structural data is needed. Methods are available for

437 capturing some of this information, including light detection and ranging (LIDAR) remote

438 sensing (Hardiman et al., 2013). However, no standardized method of collecting data has been

439 applied among sites to allow for inter-site comparisons of canopy structure. Future research

440 should consider collecting data on canopy gaps, leaf distribution, and vertical light distribution to

441 provide datasets that can be used to test whether gaps or leaf distribution within a canopy lead to

442 an enhanced carbon uptake because of increased light distribution. Without this mechanistic

443 connection, modelers cannot determine whether this missing biosphere-atmosphere connection

444 results in a significant under- or over-prediction of the future terrestrial carbon sink. As

445 scientists collect these canopy structural data, we suggest making these data publically available

446 so they can be used to better interpret patterns seen using eddy covariance data.

447 We also observed differences in diffuse light effects among sites described as the same

448 forest type (e.g., Morgan Monroe and UMBS). This argues for the consideration of site-specific

449 responses to diffuse light because plant community composition of individual forest types (or

450 ecosystems) determine unique canopy structures that can drive how strongly canopy gaps, leaf

451 distribution, and penumbral qualities influence the effect of diffuse light on ecosystem carbon

452 uptake. In particular, there were differences in afternoon carbon enhancement rates between the

453 fertilized and formerly logged Howland Forest sites, which only differ in disturbance activity. 
454 Differences in nutrient availability for plants may explain why the $\mathrm{N}$ fertilized site correlated 455 more strongly with diffuse light than the logged site. After two years of fertilization, foliage was 456 one of the most N-enriched ecosystem pools (Dail et al., 2009). Increased soil N availability 457 could lead to an increase in leaf $\mathrm{N}$, which correlates with higher concentrations of RuBisCO and 458 chlorophyll (Evans, 1989), implying an interaction between diffuse light and nutrient levels.

459 The effect of diffuse light on carbon uptake between maize and soybean also differed.

460 This may be due to species differences in canopy structure as discussed above, but could also be 461 due to the different photosynthetic pathways soy $\left(\mathrm{C}_{3}\right)$ and maize $\left(\mathrm{C}_{4}\right)$ use. Maize had a greater 462 increase in carbon uptake with diffuse light than soy did, potentially because $\mathrm{C}_{4}$ plants have a 463 higher light saturation point (Greenwald et al., 2006). Because maize would be farther away 464 from light saturation than soy, an increase in diffuse light (after accounting for cross-correlation 465 with direct light) would bring maize closer to light saturation and thus, increase photosynthesis. 466 In addition, $\mathrm{C}_{4}$ plants are better adapted to warmer environments, which may cause 467 environmental conditions, such as temperature and water availability, to change crop responses 468 to diffuse light.

469 Finally, our results show that other environmental drivers that co-vary with diffuse PAR 470 also contribute to $G P P_{r}$ at some sites. In mixed conifer forests (e.g., the Howland sites), VPD, 471 air temperature, and diffuse PAR together account for substantially more variation in $G P P_{r}$ than 472 diffuse PAR itself does, implying a lesser role for radiation and a larger one for conditions that 473 improve stomatal conductance under cloudy conditions at mixed conifer forests. In contrast, 474 VPD and air temperature, within the ranges of values characteristic of measurement periods at 475 the sites studied here, appear to have small effects on $G P P_{r}$ in the broadleaf forests. This implies 476 that the diffuse PAR effect at the broadleaf forests is due to the effect of scattered light itself. At 
477 the mixed conifer forests, the peak growing season temperature ranges from $16.5-17.6^{\circ} \mathrm{C}$ while

478 the temperature is $21.2-24.3^{\circ} \mathrm{C}$ in the broadleaf forests. Comparing these site temperatures to the

479 optimum temperature range of temperate deciduous trees $\left(20-25^{\circ} \mathrm{C}\right)$ and evergreen coniferous

480 trees $\left(10-25^{\circ} \mathrm{C}\right)$, broadleaf forests are closer to their optimum temperature range (Larcher, 2003).

481 Considering that photosynthesis varies non-linearly with temperature, the same per unit change

482 in temperature for a cooler site will lead to greater changes in GPP than in a warmer site.

483 Increases in VPD in water-limited situations, on the other hand, should cause photosynthesis to

484 drop because stomata will close to conserve water. However, VPD is actually lower in the

485 mixed forests than in the deciduous broadleaf forests, implying that air temperature is a stronger

486 driver of GPP than is VPD under our study's field conditions.

\section{5. Conclusions}

Field measurements show that diffuse PAR accounts for a substantial amount of variation

489 in GPP once the quantity of direct PAR is removed. The observed changes in the diffuse PAR

490 effect on $G P P_{r}$ vary across zenith angles, ecosystem types, and plant functional groups,

491 highlighting additional ways that ecosystem structural characteristics and the diurnal cycle

492 influence ecosystem carbon cycling. In addition, observed site-level variation suggests that

493 grouping forests together in regional or global models as the same plant functional type, without

494 considering species composition or canopy structure, may lead to inaccuracies in assessing the

495 impacts of radiation partitioning on modeled surface carbon fluxes.

496 To robustly extend these results, direct measurements of diffuse PAR and ecosystem flux

497 data are needed from a wider range of ecosystems. Furthermore, research that can evaluate

498 mechanisms (e.g, canopy gaps, leaf distribution, and species-specific characteristics) driving

499 terrestrial carbon enhancement under diffuse light will remain stagnant without consistent field 
measurements of canopy structure at sites with diffuse light and eddy covariance measurements.

501 The incorporation of standard methods for measuring canopy structure and within-canopy light

502 distribution and the availability of these data in common formats from across networks of eddy

503 covariance towers (e.g., AmeriFlux, NEON) would enable the development of better predictive

504 models of carbon exchange in relation to direct and diffuse solar radiation.

505 The interactions between diffuse light and ecosystem productivity may be of increasing

506 importance as the community composition of our terrestrial ecosystems continues to change

507 because of human land use change, natural ecological succession, and climate change. Thus, a

508 more refined understanding of how diffuse PAR modifies atmosphere-land carbon cycling and

509 subsequent representations of this relationship in models will likely advance our understanding

510 of how human management of ecosystems will influence the land carbon sink as well as improve

511 future calculations of atmospheric $\mathrm{CO}_{2}$ concentrations for global climate projections.

\section{Acknowledgments}

513 We thank the FLUXNET community for their dedicated efforts in collecting and

514 providing quality-controlled eddy covariance data for ecosystem research. We also thank the

515 University of Michigan Center for Statistical Consultation and Research (Dr. Corey Powell and

516 Dr. Kerby Shedden) for input on statistical techniques, Dr. Christoph Vogel for providing

517 updated PAR data for UMBS, and Alex Fotis for early discussions and data organization for this

518 paper. Support for SJC was provided in part by the University of Michigan Graham

519 Sustainability Institute. Funding for data collection at UMBS was provided by the National

520 Science Foundation grant DEB-0911461, the U.S. Department of Energy's (DOE) Office of

521 Science Biological and Environmental Research (BER) project DE-SC0006708 and AmeriFlux

522 National Core Flux Site award through Lawrence Berkeley National Laboratory contract 
$523 \# 7096915$, and National Oceanic and Atmospheric Administration grant NA11OAR4310190.

524 Research at the Howland Forest is supported by the DOE's Office of Science BER. The Mead

525 US-Ne1, US-Ne2, and US-Ne3 AmeriFlux sites were supported by the DOE Office of Science

526 (BER; Grant Nos. DE-FG03-00ER62996, DE-FG02-03ER63639, and DE-EE0003149), DOE-

527 EPSCoR (Grant No. DE-FG02-00ER45827), and NASA NACP (Grant No. NNX08AI75G).

528 The Morgan Monroe team thanks the Indiana Department of Natural Resources for supporting

529 and hosting the UM-MMS AmeriFlux site, and the U.S. DOE for funding operations through the

530 Terrestrial Ecosystem Science program and the AmeriFlux Management Project. 
532

533

534

535

536

537

538

\section{Appendices}

Appendix 1: Values of $\alpha$ and $\gamma$ predicted by best-fit rectangular hyperbolas describing the response of GPP to direct PAR. The $\alpha$ represents the quantum yield and $\gamma$ represents the maximum GPP value. All $\alpha$ and $\gamma$ values listed have $p<6.02 \times 10^{-4}$ (Bonferroni-corrected critical value), except for those in italics, which have $p<0.01$ and those in bold, which were not significant because $p>0.05$. NS indicates we were unable to fit a light response curve.

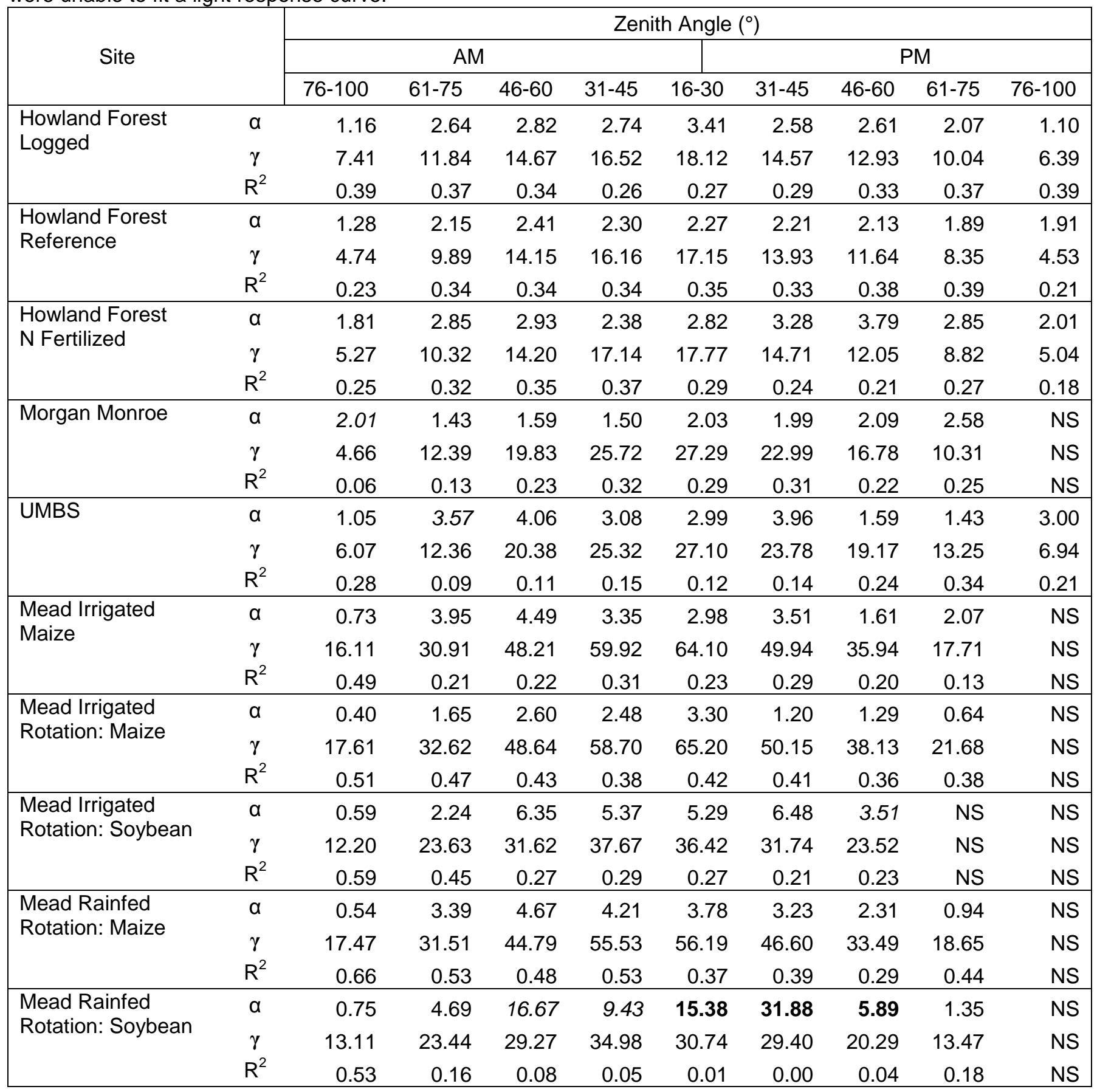




\section{References}

Alton, P.B., 2008. Reduced carbon sequestration in terrestrial ecosystems under overcast skies compared to clear skies. Agricultural and Forest Meteorology, 148(10): 1641-1653.

Alton, P.B., North, P., Kaduk, J. and Los, S., 2005. Radiative transfer modeling of direct and diffuse sunlight in a Siberian pine forest. Journal of Geophysical Research: Atmospheres, 110(D23): D23209.

Alton, P.B., North, P.R. and Los, S.O., 2007. The impact of diffuse sunlight on canopy light-use efficiency, gross photosynthetic product and net ecosystem exchange in three forest biomes. Global Change Biology, 13(4): 776-787.

Arora, V.K. and Boer, G.J., 2010. Uncertainties in the 20th century carbon budget associated with land use change. Global Change Biology, 16(12): 3327-3348.

Bai, Y., Wang, J., Zhang, B., Zhang, Z. and Liang, J., 2012. Comparing the impact of cloudiness on carbon dioxide exchange in a grassland and a maize cropland in northwestern China. Ecological Research, 27(3): 615-623.

Baldocchi, D.D., 2003. Assessing the eddy covariance technique for evaluating carbon dioxide exchange rates of ecosystems: past, present and future. Global Change Biology, 9(4): 479-492.

Bonan, G.B., Oleson, K.W., Fisher, R.A., Lasslop, G. and Reichstein, M., 2012. Reconciling leaf physiological traits and canopy flux data: Use of the TRY and FLUXNET databases in the Community Land Model version 4. Journal of Geophysical Research: Biogeosciences, 117(G2): G02026.

Butt, N. et al., 2010. Diffuse radiation and cloud fraction relationships in two contrasting Amazonian rainforest sites. Agricultural and Forest Meteorology, 150(3): 361-368.

Campbell, G.S. and Norman, J.M., 1998. An introduction to environmental biophysics. An introduction to environmental biophysics.(Ed. 2).

Curtis, P.S. et al., 2002. Biometric and eddy-covariance based estimates of annual carbon storage in five eastern North American deciduous forests. Agricultural and Forest Meteorology, 113(1-4): 3-19.

Dai, Y., Dickinson, R.E. and Wang, Y.-P., 2004. A two-big-leaf model for canopy temperature, photosynthesis, and stomatal conductance. Journal of Climate, 17(12).

Dail, D.B. et al., 2009. Distribution of nitrogen-15 tracers applied to the canopy of a mature spruce-hemlock stand, Howland, Maine, USA. Oecologia, 160(3): 589-599.

Davin, E.L. and Seneviratne, S.I., 2012. Role of land surface processes and diffuse/direct radiation partitioning in simulating the European climate. Biogeosciences, 9(5): 16951707.

Dengel, S. and Grace, J., 2010. Carbon dioxide exchange and canopy conductance of two coniferous forests under various sky conditions. Oecologia, 164(3): 797-808.

Denholm, J.V., 1981. THE INFLUENCE OF PENUMBRA ON CANOPY PHOTOSYNTHESIS .1. THEORETICAL CONSIDERATIONS. Agricultural Meteorology, 25(3): 145-166.

Dragoni, D. et al., 2011. Evidence of increased net ecosystem productivity associated with a longer vegetated season in a deciduous forest in south-central Indiana, USA. Global Change Biology, 17(2): 886-897.

Evans, J., 1989. Photosynthesis and nitrogen relationships in leaves of C3 plants. Oecologia, 78(1): 9-19. 
Garrity, S.R. et al., 2011. A comparison of multiple phenology data sources for estimating seasonal transitions in deciduous forest carbon exchange. Agricultural and Forest Meteorology, 151(12): 1741-1752.

Gough, C.M. et al., 2013. Sustained carbon uptake and storage following moderate disturbance in a Great Lakes forest. Ecological Applications, 23(5): 1202-1215.

Greenwald, R. et al., 2006. The influence of aerosols on crop production: A study using the CERES crop model. Agricultural Systems, 89(2-3): 390-413.

$\mathrm{Gu}$, L. et al., 2002. Advantages of diffuse radiation for terrestrial ecosystem productivity. Journal of Geophysical Research: Atmospheres, 107(D6): ACL 2-1-ACL 2-23.

$\mathrm{Gu}, \mathrm{L}$. et al., 2003. Response of a Deciduous Forest to the Mount Pinatubo Eruption: Enhanced Photosynthesis. Science, 299(5615): 2035-2038.

Gu, L., Fuentes, J.D., Shugart, H.H., Staebler, R.M. and Black, T.A., 1999a. Responses of net ecosystem exchanges of carbon dioxide to changes in cloudiness: Results from two North American deciduous forests. Journal of Geophysical Research: Atmospheres, 104(D24): 31421-31434.

Gu, L., Fuentes, J.D., Shugart, H.H., Staebler, R.M. and Black, T.A., 1999b. Responses of net ecosystem exchanges of carbon dioxide to changes in cloudiness: Results from two North American deciduous forests. J. Geophys. Res., 104(D24): 31421-31434.

Hardiman, B.S. et al., 2013. Maintaining high rates of carbon storage in old forests: A mechanism linking canopy structure to forest function. Forest Ecology and Management, 298(0): 111-119.

Hollinger, D.Y. et al., 2004. Spatial and temporal variability in forest-atmosphere CO2 exchange. Global Change Biology, 10(10): 1689-1706.

Hollinger, D.Y. et al., 1994. Carbon Dioxide Exchange between an Undisturbed Old-Growth Temperate Forest and the Atmosphere. Ecology, 75(1): 134-150.

Hutchison, B.A., Matt, D.R. and McMillen, R.T., 1980. Effects of sky brightness distribution upon penetration of diffuse radiation through canopy gaps in a deciduous forest. Agricultural Meteorology, 22(2): 137-147.

Jenkins, J.P. et al., 2007. Refining light-use efficiency calculations for a deciduous forest canopy using simultaneous tower-based carbon flux and radiometric measurements. Agricultural and Forest Meteorology, 143(1-2): 64-79.

Knohl, A. and Baldocchi, D.D., 2008. Effects of diffuse radiation on canopy gas exchange processes in a forest ecosystem. J. Geophys. Res., 113(G2): G02023.

Larcher, W., 2003. Physiolgical Plant Ecology. Springer, Berlin.

Law, B.E. et al., 2002. Environmental controls over carbon dioxide and water vapor exchange of terrestrial vegetation. Agricultural and Forest Meteorology, 113(1-4): 97-120.

Le Quéré, C. et al., 2013. Global carbon budget 2013. Earth Syst. Sci. Data Discuss., 6(2): 689760.

Matheny, A.M. et al., 2014. Characterizing the diurnal patterns of errors in the prediction of evapotranspiration by several land-surface models: An NACP analysis. Journal of Geophysical Research: Biogeosciences, 119(7): 2014JG002623.

Matsui, T., Beltrán-Przekurat, A., Niyogi, D., Pielke, R.A., Sr. and Coughenour, M., 2008. Aerosol light scattering effect on terrestrial plant productivity and energy fluxes over the eastern United States. J. Geophys. Res., 113(D14): D14S14.

Mercado, L.M. et al., 2009. Impact of changes in diffuse radiation on the global land carbon sink. Nature, 458(7241): 1014-U87. 
Min, Q. and Wang, S., 2008. Clouds modulate terrestrial carbon uptake in a midlatitude hardwood forest. Geophys. Res. Lett., 35(2): L02406.

Misson, L., Lunden, M., McKay, M. and Goldstein, A.H., 2005. Atmospheric aerosol light scattering and surface wetness influence the diurnal pattern of net ecosystem exchange in a semi-arid ponderosa pine plantation. Agricultural and Forest Meteorology, 129(1-2): 69-83.

Niyogi, D. et al., 2004. Direct observations of the effects of aerosol loading on net ecosystem CO2 exchanges over different landscapes. Geophysical Research Letters, 31(20).

Oliphant, A.J. et al., 2011. The role of sky conditions on gross primary production in a mixed deciduous forest. Agricultural and Forest Meteorology, 151(7): 781-791.

R Development Core Team, 2012. R: A language and environment for statistical computing. $\mathrm{R}$ Foundation for Statistical Computing, Vienna, Austria.

Richardson, A.D. et al., 2013. Climate change, phenology, and phenological control of vegetation feedbacks to the climate system. Agricultural and Forest Meteorology, 169(0): 156-173.

Rocha, A.V., Su, H.-B., Vogel, C.S., Schmid, H.P. and Curtis, P.S., 2004. Photosynthetic and Water Use Efficiency Responses to Diffuse Radiation by an Aspen-Dominated Northern Hardwood Forest. Forest Science, 50(6): 793-801.

Ruimy, A., Jarvis, P.G., Baldocchi, D.D. and Saugier, B., 1995. CO2 Fluxes over Plant Canopies and Solar Radiation: A Review. In: M. Begon and A.H. Fitter (Editors), Advances in Ecological Research. Academic Press, pp. 1-68.

Sarmiento, J.L. et al., 2010. Trends and regional distributions of land and ocean carbon sinks. Biogeosciences, 7(8): 2351-2367.

Scott, N.A. et al., 2004. Changes in Carbon Storage and Net Carbon Exchange One Year After an Initial Shelterwood Harvest at Howland Forest, ME. Environmental Management, 33(1): S9-S22.

Steiner, A.L. and Chameides, W.L., 2005. Aerosol-induced thermal effects increase modelled terrestrial photosynthesis and transpiration. Tellus B, 57(5): 404-411.

Urban, O. et al., 2007. Ecophysiological controls over the net ecosystem exchange of mountain spruce stand. Comparison of the response in direct vs. diffuse solar radiation. Global Change Biology, 13(1): 157-168.

Urban, O. et al., 2012. Impact of clear and cloudy sky conditions on the vertical distribution of photosynthetic CO2 uptake within a spruce canopy. Functional Ecology, 26(1): 46-55.

Verma, S.B. et al., 2005. Annual carbon dioxide exchange in irrigated and rainfed maize-based agroecosystems. Agricultural and Forest Meteorology, 131(1-2): 77-96.

Wang, K., Dickinson, R.E. and Liang, S., 2008. Observational evidence on the effects of clouds and aerosols on net ecosystem exchange and evapotranspiration. Geophys. Res. Lett., 35(10): L10401.

Way, D.A. and Pearcy, R.W., 2012. Sunflecks in trees and forests: from photosynthetic physiology to global change biology. Tree physiology, 32(9): 1066-1081.

Williams, M., Rastetter, E.B., Van der Pol, L. and Shaver, G.R., 2014. Arctic canopy photosynthetic efficiency enhanced under diffuse light, linked to a reduction in the fraction of the canopy in deep shade. New Phytologist, 202(4): 1267-1276.

Yan, H. et al., 2012. Global estimation of evapotranspiration using a leaf area index-based surface energy and water balance model. Remote Sensing of Environment, 124: 581-595. 
677 Zhang, M. et al., 2011. Effects of cloudiness change on net ecosystem exchange, light use 678 efficiency, and water use efficiency in typical ecosystems of China. Agricultural and 679 Forest Meteorology, 151(7): 803-816.

680 Zhang, Q., Manzoni, S., Katul, G., Porporato, A. and Yang, D., 2014. The hysteretic

681 evapotranspiration-Vapor pressure deficit relation. Journal of Geophysical Research:

$682 \quad$ Biogeosciences, 119(2): 2013JG002484.

683 Zhang, Y., Wen, X.Y. and Jang, C.J., 2010. Simulating chemistry-aerosol-cloud-radiationclimate feedbacks over the continental U.S. using the online-coupled Weather Research Forecasting Model with chemistry (WRF/Chem). Atmospheric Environment, 44(29): 